\title{
Nouvel outil de formation sur douleur et cancer
}

\section{New training tool for the management of pain in cancer}

Comment rassurer un patient? Pourquoi la voie orale est-elle la voie à privilégier ? Quelles sont les associations médicamenteuses à éviter ? Est-ce qu'un patient peut prendre de la morphine LI chaque fois qu'il en a besoin ? Le kit Douleur et Cancer, conçu pour la formation des professionnels de santé en lien avec des patients atteints d'un cancer, répond à ces questions.

Douleur chronique, aiguë, neuropathique, nociceptive, la douleur est multiple en cancérologie. Parmi ces douleurs se trouvent également les douleurs iatrogènes, induites par les soins. Pose de cathéter, pansement, biopsie, ponction, rééducation active, effets indésirables d'un médicament sont autant de causes susceptibles de déclencher la douleur.
Quelle qu'elle soit, la douleur doit être évaluée et prise en charge. Dans le cas de la douleur liée au cancer, le professionnel de santé peut avoir recours à des opioïdes, tels que la morphine, qui se révèlent efficaces.

Cette utilisation soulève souvent des interrogations de la part des professionnels de santé, interrogations auxquelles le kit « Douleur et Cancer : le maniement de la morphine et des opioïdes en général » répond pour combattre les idées reçues.

Destiné à la formation et à l'information des professionnels de santé, le kit « Douleur et Cancer : le maniement de la morphine et des opioïdes en général » se présente comme un outil pratique et didactique à utiliser comme support de formation.

Ce kit de formation est téléchargeable sur le site de l'institut UPSA de la Douleur : www.institut-upsa-douleur.org

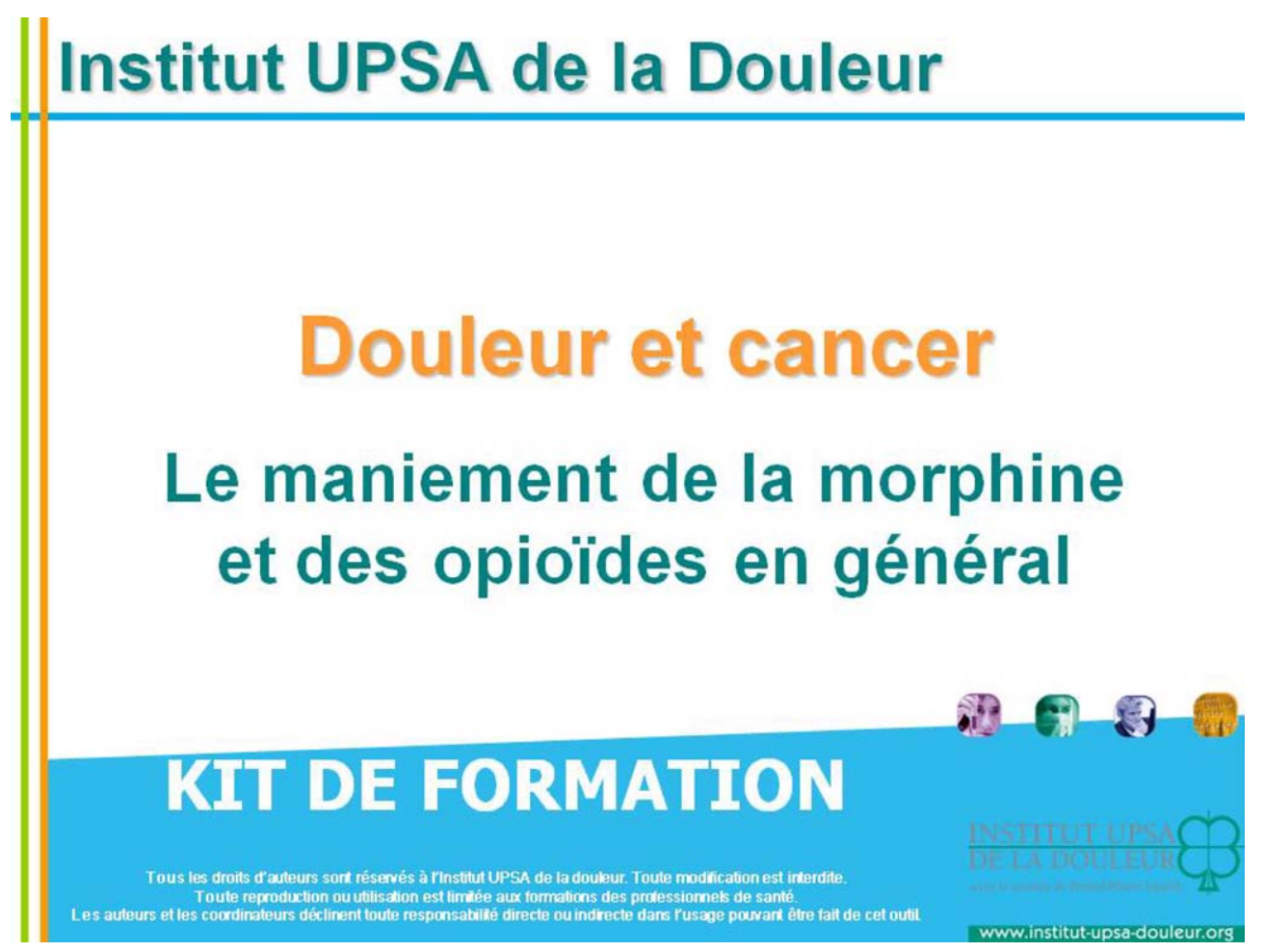

